\title{
Stark broadening of Xe II lines ${ }^{\star}$
}

\author{
L.Č. Popović and M.S. Dimitrijević \\ Astronomical Observatory, Volgina 7, 11000 Belgrade, Yugoslavia \\ Received May 10; accepted September 13, 1995
}

\begin{abstract}
We present here Stark widths and shifts for 20 Xe II multiplets which are of interest for laboratory plasma research as well as for the analysis of $\mathrm{Hg}-\mathrm{Mn}$ stars spectra. For calculations the modified semiempirical approach was used. The obtained results are compared with the available experimental data.
\end{abstract}

Key words: atomic data — plasmas — stars: chemically peculiar

\section{Introduction}

Stark broadening data are of interest for diagnostic and modelling of laboratory and stellar plasma, investigation of its physical properties and abundance determination. Spectral lines of Xe II are present in spectra of hot $(\mathrm{Hg}$ - Mn) stars, (see, e.g., Whitford 1962; Aller 1970; Heacox 1979; Dobrichev et al. 1990), where Stark broadening is the main pressure broadening mechanism. On the basis of analysis of the Xe II spectral lines one can conclude that the abundance of $\mathrm{Xe}$ in $\mathrm{Hg}$ - Mn stars is about two times larger than in the Sun (Heacox 1979). Stark broadening of Xe II lines is important for laboratory plasma investigation (see e.g. Konjević \& Uzelac 1990) as well.

A number of experimental and theoretical papers concerning Stark widths and shifts of Xe II lines have been published (e.g. Lesage et al. 1981; Miller et al. 1981; Richou et al. 1984; Nick \& Helbig 1986; Pittman \& Konjević 1986; Vitel \& Skowronek 1987; Manola et al. 1988; Lesage et al. 1989; Di Rocco 1990a, b; Konjević \& Uzelac 1990; Bertuccelli et al. 1991; Mar et al. 1992; Gigosos et al. 1994). We present here Stark broadening data for 20 Xe II multiplets. Due to the lack of reliable atomic data for Xe II lines, it is not possible to apply a semi-classical perturbation approach (Griem 1974; SahalBréchot $1969 \mathrm{a}, \mathrm{b})$ in an adequate way, so the modified semiempirical approach (Dimitrijević \& Konjević 1980; Dimitrijević \& Kršljanin 1986) will be used here.

Our results are compared with numerous available experimental data (Lesage et al. 1981; Miller et al. 1981; Richou et al. 1984; Nick \& Helbig 1986; Vitel \& Skowronek

Send offprint requests to: L.Č. Popović

${ }^{\star}$ Table 1 is only available in electronic form and Table 2 is also available in electronic form via anonymous ftp 130.79.128.5 at the CDS in Strasbourg
1987; Manola et al. 1988; Lesage et al. 1989; Di Rocco 1990b; Konjević \& Uzelac 1990; Bertuccelli et al. 1991; Gigosos et al. 1994).

\section{Results and discusion}

Atomic energy levels for calculation have been taken from Hansen \& Persson (1987), where it is indicated that the $j K$ coupling scheme is the most appropriate for Xe II. Consequently the $j K$ coupling scheme was used for matrix element calculation. An illustration of the influence of the applied coupling scheme on the Stark width calculation is shown in Figs. 1-4. In these figures, Stark widths for several Xe II lines (6s-6p transition), with $j K$ and $L S$ coupling scheme for the matrix element calculations are compared. As one can see from Figs. 1-4 the differences are relatively small in comparison with the accuracy of the method $( \pm 50 \%)$. Moreover, the calculations within $j K$ coupling scheme are in slightly better agreement with experimental data.

Our results for Stark widths and shifts of Xe II spectral lines are presented in Table 1 (accessible only in electronic form). The values obtained for temperatures from $5000 \mathrm{~K}$ up to $50000 \mathrm{~K}$ and an electron density of $10^{23} \mathrm{~m}^{-3}$ are compared (in Table 2 and in Figs. 1-4) with the available experimental data (Lesage et al. 1981; Miller et al. 1981; Richou et al. 1984; Nick \& Helbig 1986; Vitel \& Skowronek 1987; Manola et al. 1988; Lesage et al. 1989; Di Rocco 1990b; Konjević \& Uzelac 1990; Bertuccelli et al. 1991; Gigosos et al. 1994). Since we found that the ion broadening contribution is about several per cent, only the electron broadening contribution is given. As evident, the calculated Stark widths give satisfactory agreement with the experimental ones. From Table 2, it can be noticed that for the $6 \mathrm{~s}-6 \mathrm{p}$ transition a large disagreement 
Table 2. Comparison of measured $(m)$ and theoretical $($ th) values for Stark widths $(w)$ and shifts $(d)$. Experimental results $w_{m}, d_{m}$ are taken from: (1) - Nick \& Helbig 1986, (2) - Di Rocco 1990b, (3) - Gigosos et al. 1994, (4) - Lesage et al. 1981, (5) - Lesage et al. 1989, (6) - Miller et al. 1981, (7) - Bertuccelli et al. 1991, (8) - Richou et al. 1984, (9) - Vitel \& Skowronek 1987, (10) - Konjević \& Uzelac 1990, (11) - Manola et al. 1988, the electron density is $10^{23} \mathrm{~m}^{-3}$

\begin{tabular}{|c|c|c|c|c|c|c|c|}
\hline Transition & $\lambda(\mathrm{nm})$ & $T(1000 \mathrm{~K})$ & $w_{m}(\mathrm{~nm})$ & $d_{m}(\mathrm{~nm})$ & $w_{m} / w_{t h}$ & $d_{m} / d_{t h}$ & Ref. \\
\hline$\left({ }^{3} P_{2}\right) 6 s[2]-\left({ }^{3} P_{2}\right) 6 p[1]$ & $\begin{array}{l} \\
421.56 \\
537.24\end{array}$ & $\begin{array}{l}10.0 \\
10.0 \\
10.0 \\
11.0 \\
11.0 \\
11.2 \\
14.5 \\
15.0 \\
\\
10.0 \\
14.5 \\
\\
8.0 \\
10.0 \\
10.0 \\
10.0 \\
11.0 \\
11.0 \\
11.2 \\
14.5 \\
15.0 \\
\end{array}$ & $\begin{array}{c}0.0463 \\
0.067 \\
0.048 \\
\\
0.069 \\
0.088 \\
0.065 \\
0.093 \\
0.0588\end{array}$ & $\begin{array}{c}- \\
0.00 \\
>-0.001 \\
-0.00178 \\
-0.00866 \\
>-0.001 \\
\end{array}$ & $\begin{array}{l}1.6 \\
\\
1.0 \\
0.9 \\
\\
1.3 \\
1.7 \\
1.2 \\
1.8 \\
1.3\end{array}$ & 0.2 & $\begin{array}{l}(1) \\
(2) \\
(3) \\
(4) \\
(5) \\
(6) \\
(7) \\
(3) \\
\\
(2) \\
(7) \\
\\
(8) \\
(1) \\
(2) \\
(3) \\
(4) \\
(5) \\
(6) \\
(7) \\
(3) \\
\end{array}$ \\
\hline$\left({ }^{3} P_{2}\right) 6 s[2]-\left({ }^{3} P_{2}\right) 6 p[2]$ & 529.2 & $\begin{array}{c}10.0 \\
10.0 \\
10.0 \\
11.0 \\
11.0 \\
11.2 \\
12.6 \\
13.0 \\
13.9 \\
14.8 \\
15.0 \\
15.8 \\
\\
8.0 \\
10.0 \\
10.0 \\
11.0 \\
13.0\end{array}$ & $\begin{array}{c}0.0427 \\
0.0805 \\
0.079 \\
0.088 \\
0.093 \\
0.0411 \\
0.0591 \\
0.039 \\
0.045 \\
\\
0.041 \\
\\
0.060 \\
\\
0.0679 \\
0.064 \\
0.0591\end{array}$ & $\begin{array}{c}-0.031 \\
-0.00274 \\
-0.00488 \\
-0.00651 \\
-0.007 \\
-0.00508\end{array}$ & $\begin{array}{l}0.8 \\
1.6 \\
1.5 \\
1.7 \\
1.7 \\
0.9 \\
1.2 \\
0.9 \\
1.1 \\
\\
1.0 \\
\\
1.0 \\
\\
1.3 \\
1.2 \\
1.2\end{array}$ & $\begin{array}{l}0.2 \\
0.3 \\
0.4 \\
0.5 \\
0.3\end{array}$ & $\begin{array}{r}(1) \\
(2) \\
(3) \\
(5) \\
(4) \\
(6) \\
(9) \\
(10) \\
(9) \\
(9) \\
(3) \\
(9) \\
\\
(8) \\
(2) \\
(3) \\
(5) \\
(10)\end{array}$ \\
\hline
\end{tabular}


Table 2. continued

\begin{tabular}{|c|c|c|c|c|c|c|c|}
\hline Transition & $\lambda(\mathrm{nm})$ & $\mathrm{T}(1000 \mathrm{~K})$ & $w_{m}(\mathrm{~nm})$ & $d_{m}(\mathrm{~nm})$ & $w_{m} / w_{t h}$ & $d_{m} / d_{t h}$ & Ref. \\
\hline & 597.6 & $\begin{array}{l}13.4 \\
14.3 \\
14.8 \\
15.0 \\
15.8 \\
\\
10.0 \\
10.0 \\
10.0 \\
14.5 \\
15.0\end{array}$ & $\begin{array}{c}0.0408 \\
0.0388 \\
0.0468 \\
0.0407 \\
\\
0.0575 \\
0.0791 \\
0.070\end{array}$ & $\begin{array}{c}-0.00714 \\
-0.00597 \\
-0.00851 \\
-0.008 \\
-0.00678 \\
-0.0214 \\
-.009\end{array}$ & $\begin{array}{l}0.9 \\
0.9 \\
1.1 \\
\\
1.0 \\
\\
0.9 \\
\\
1.2 \\
1.3\end{array}$ & $\begin{array}{c}0.4 \\
0.4 \\
0.5 \\
0.5 \\
0.4\end{array}$ & $\begin{array}{l}(9) \\
(9) \\
(9) \\
(3) \\
(9) \\
\\
(1) \\
(2) \\
(3) \\
(7) \\
(3)\end{array}$ \\
\hline$\left({ }^{3} P_{2}\right) 6 s[2]-\left({ }^{3} P_{2}\right) 6 p[3]$ & 484.4 & $\begin{array}{l}10.0 \\
10.0 \\
10.0 \\
11.0 \\
11.0 \\
11.2 \\
12.5 \\
13.0 \\
13.4 \\
14.3 \\
14.8 \\
15.0 \\
15.8 \\
\\
10.0 \\
10.0 \\
14.5 \\
15.0 \\
\\
8.0 \\
8.0 \\
9.0 \\
9.9 \\
10.0 \\
10.0 \\
10.0 \\
\end{array}$ & $\begin{array}{c}0.0367 \\
0.0826 \\
0.072 \\
0.081 \\
0.086 \\
0.0556 \\
0.0536 \\
0.0370 \\
0.0358 \\
0.0383 \\
\\
0.0390 \\
\\
0.0465 \\
0.0469 \\
\\
0.090 \\
0.115 \\
0.096 \\
0.076 \\
0.0556 \\
0.0897 \\
\end{array}$ & $\begin{array}{c}.0258 \\
\\
\\
\\
0.00 \\
-0.00312 \\
0.00 \\
-0.003 \\
0.00 \\
-0.0622 \\
\\
-0.006\end{array}$ & $\begin{array}{l}0.8 \\
1.8 \\
1.5 \\
1.8 \\
1.9 \\
1.2 \\
1.1 \\
1.0 \\
1.0 \\
1.0 \\
\\
1.1 \\
\\
1.0 \\
1.2 \\
\\
1.3 \\
1.7 \\
1.5 \\
1.3 \\
1.0 \\
1.5 \\
\end{array}$ & $\begin{array}{c} \\
- \\
0.3 \\
- \\
0.3 \\
- \\
4.3\end{array}$ & $\begin{array}{r}(1) \\
(2) \\
(3) \\
(5) \\
(4) \\
(6) \\
(10) \\
(10) \\
(9) \\
(9) \\
(9) \\
(3) \\
(9) \\
\\
(2) \\
(3) \\
(7) \\
(3) \\
\\
(8) \\
(11) \\
(11) \\
(11) \\
(1) \\
(2) \\
(3) \\
\end{array}$ \\
\hline
\end{tabular}

\footnotetext{
${ }^{*}$ The measured and the calculated values of Stark shift have different sign.
} 
Table 2. continued

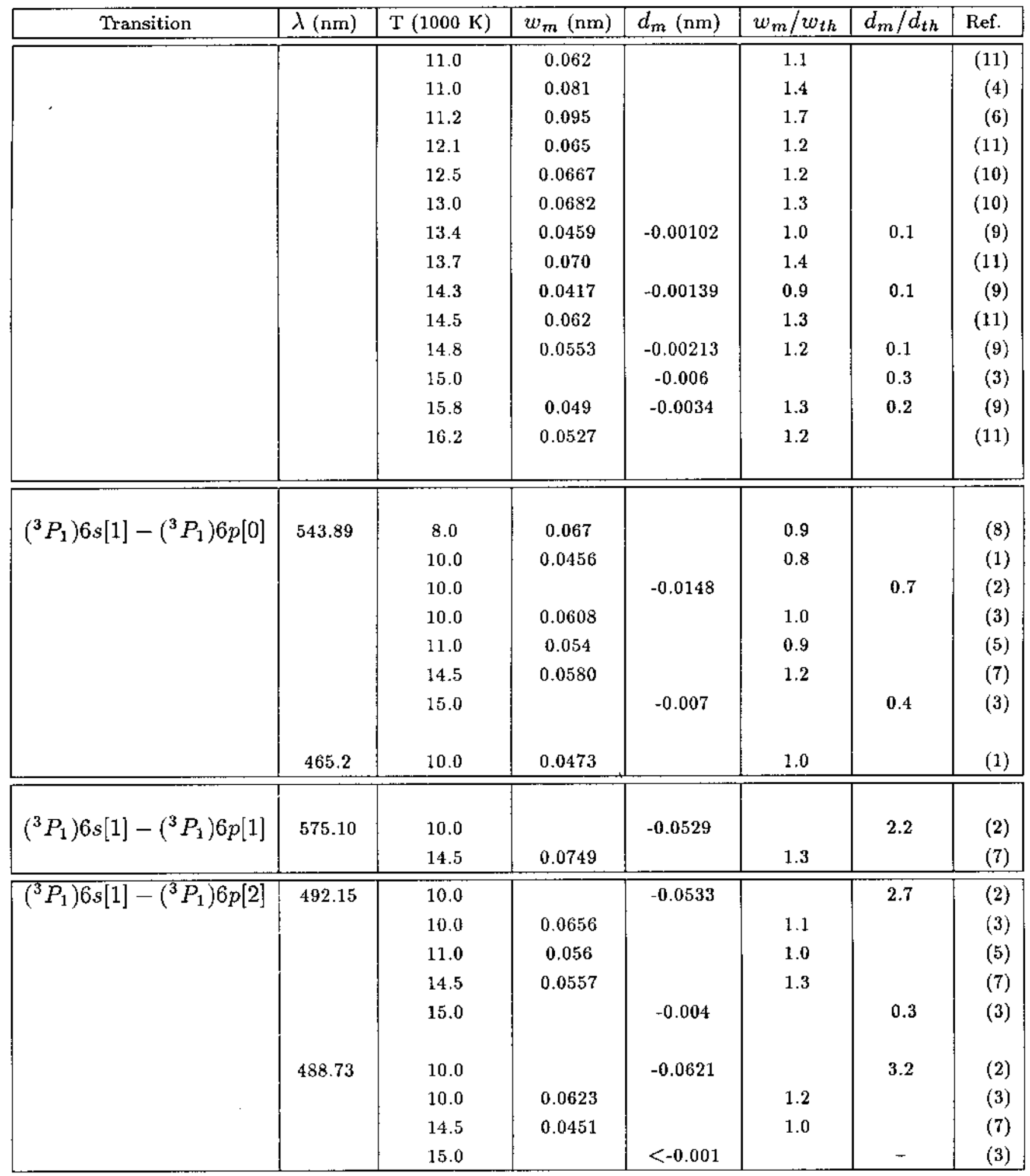


Table 2. continued

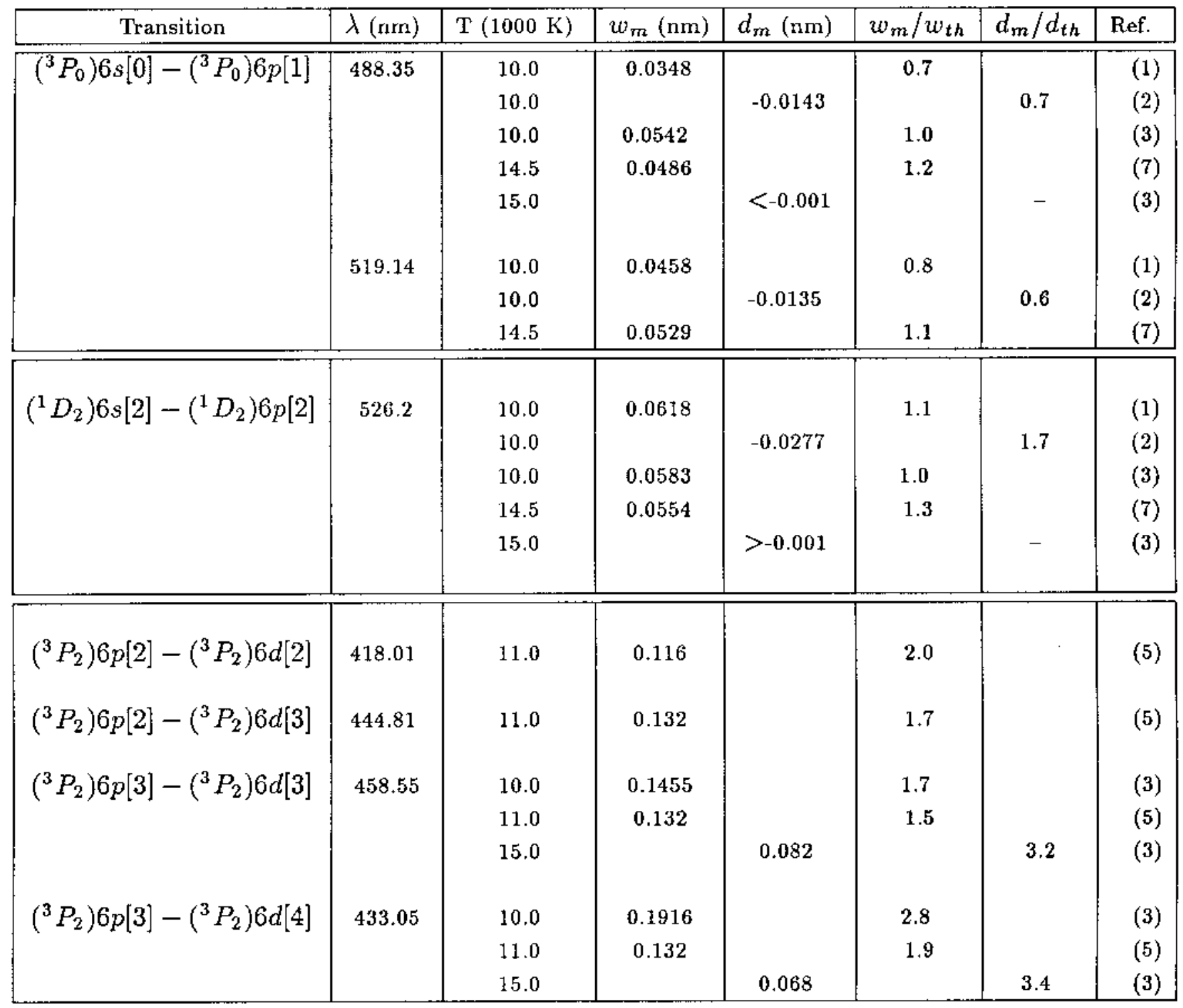

between our theoretical Stark widths and experimental data exists only with Lesage et al. (1981) and Miller et al (1981). Here, the ratio of measured and our calculated Stark widths is $w_{\exp } / w_{\text {th }}=2.1$ respectively for $\lambda=$ $460.3 \mathrm{~nm}$. Moreover, these experimental results are larger than our calculated results from $70 \%$ to $100 \%$. Since more recent results exist from basically the same group (Richou et al. 1984; Manola et al. 1988; Lesage et al. 1989) we will exclude Lesage et al. (1981) and Miller et al. (1981) from further considerations. Excluding these measurements, we may conclude that our theoretical Stark width calculations are in good agreement with experimental data for $6 \mathrm{~s}-6 \mathrm{p}$ transitions. It should be noticed that our results are in excellent agreement with experimental data of Nick \& Helbig (1986) and Richou et al. (1984) which have the highest accuracy among critically selected experimental data for Xe II lines in Konjević \& Wiese (1990). Our theoretical results are in excellent agreement as well with the experimental values of Vitel \& Skowronek (1987) and Konjević \& Uzelac (1990). The agreement with Manola et al. (1988), Lesage et al. (1989), Bertuccelli et al. (1991) and Gigosos et al. (1994) is also within the error bars of theory and experiment. For $6 \mathrm{p}-6 \mathrm{~d}$ transitions there exist only experimental data by Lesage et al. (1989) and Gigosos et al. (1994). The ratio of measured and calculated data varies between 1.5 and 2.8. Since all data for $6 \mathrm{p}-6 \mathrm{~d}$ transitions are obtained at temperatures of $10000 \mathrm{~K}$ and $11000 \mathrm{~K}$, new measurements at different temperatures are of interest. Experimental data being within a narrower temperature range between $8000 \mathrm{~K}$ and 


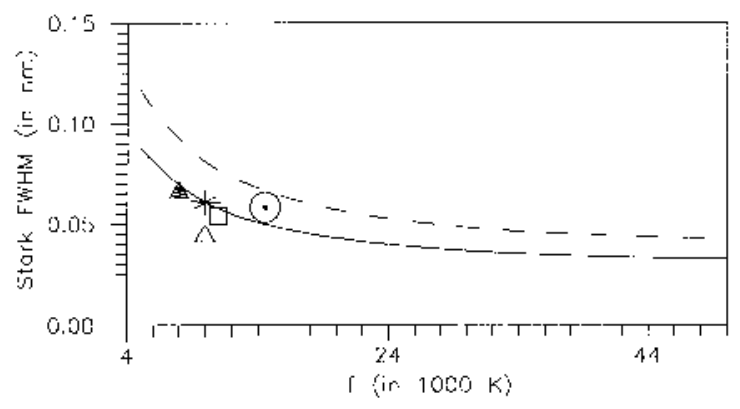

Fig. 1. Stark full width (FWHM) for Xe II $\lambda=543.8 \mathrm{~nm}$ spectral line as a function of temperature, at an electron density of $N=10^{23} \mathrm{~m}^{-3}$. The used notation is: $(-)$ - present results calculated within the $j K$ coupling approximation, $(---)$ - present results within the $L S$ coupling approximation. Experimental data: $(+)$ - Lesage et al. 1981, $(\times)$ - Miller et al. 1981, $(\mathbf{\Delta})$ - Richou et al. 1984, $(\Delta)$ - Nick \& Helbig 1986, (○) - Vitel \& Skowronek 1987, (口) - Manola et al. 1988, ( $\square$ ) - Lesage et al. 1989, $(\oplus)$ - Konjević \& Uzelac 1990, $(\odot)$ Bertuccelli et al. 1991, (*) - Gigosos et al. 1994

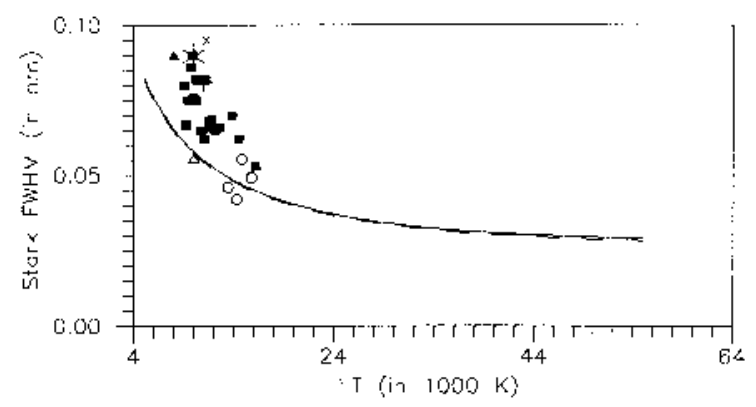

Fig. 2. Same as in Fig. 1, but for line $\lambda=541.9 \mathrm{~nm}$

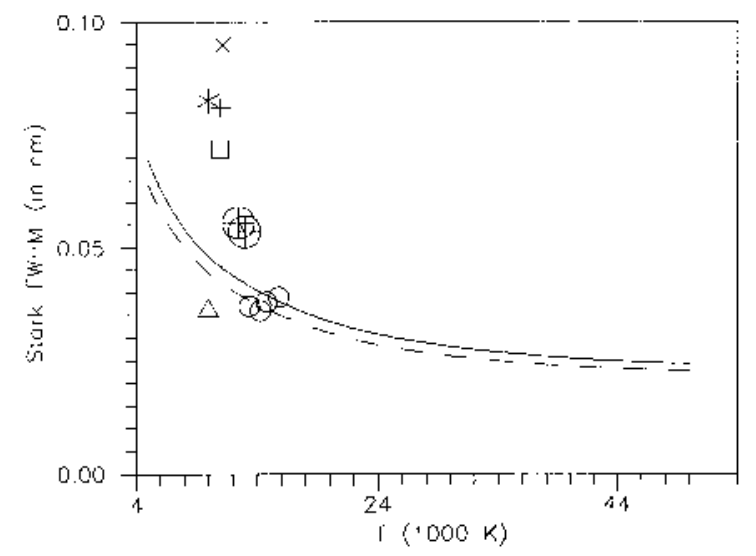

Fig. 3. Same as in Fig. 1, but for line $\lambda=484.4 \mathrm{~nm}$

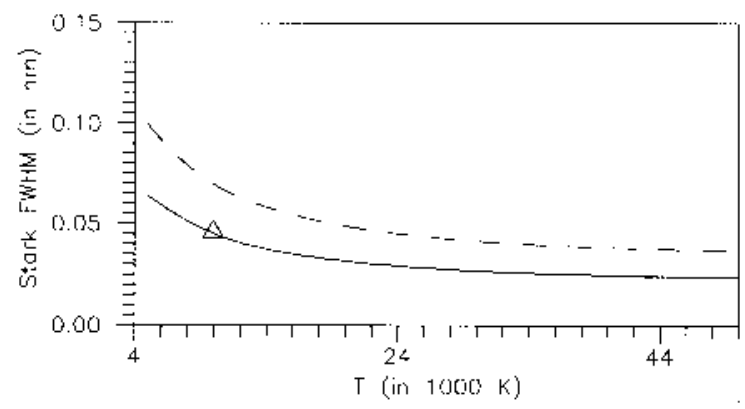

Fig. 4. Same as in Fig. 1, but for line $\lambda=465.2 \mathrm{~nm}$

$16200 \mathrm{~K}$, where the Stark widths decrease quickly, it is important to provide experimental data for higher temperatures in order to check the dependence on temperature over a wider range. Without the data of Lesage et al. (1981) and Miller et al. (1981) the average value of the ratio of experimental and theoretical results is $w_{\text {exp }} / w_{\text {th }}=1.29 \pm 0.07$ the indicated error represents an average quadratic error $\delta$ calculated from

$$
\delta=\sqrt{\frac{\sum_{i=1}^{m} \Delta_{i}^{2}}{m(m-1)}}
$$

where $\Delta_{i}$ is the difference between the $i^{\text {th }}$ average ratio for a line and the average ratio for all lines. If there are several values at different temperature from the same reference for the same line, before making an average ratio for the line, these values have been averaged. For $6 s-6 p$ transitions alone the average ratio, excluding the above mentioned experiments, is $1.15 \pm 0.05$.

For Xe II Stark shifts, we have only experimental data of Vitel \& Skowronek (1987), estimated by Konjević \& Wiese (1990) to be of low accuracy, data of Di Rocco (1990b) and data of Gigosos et al. (1994). The typical shifts are smaller by an order of magnitude than the widths or around zero and the difference between the two experiments is even one order of magnitude. The agreement with our shift calculations is very poor and new reliable shift measurements are of interest. One should notice also that the theoretical shifts are generally of lower accuracy than widths, since for the shift contributions from different perturbing terms have different signs. If shifts are much smaller than widths, i.e. if contributions with both signs are similar, the shift accuracy is much lower.

\section{References}

Aller M.F., 1970, A\&A 6, 67

Bertuccelli D., Bertuccelli G., Di Rocco H.O., 1991, Phys. Scr. 43, 469

Dimitrijević M.S., Konjević N., 1980, JQSRT 24, 451

Dimitrijević M.S., Kršljanin V., 1986, A\&A 165, 269

Di Rocco H.O., 1990a, Spectrosc. Lett. 23, 283

Di Rocco H.O., 1990b, Il Nuovo Cimento 12D, 1485 
Dobrichev V.M., Ryabchikova T.A., Rajkova D.V., 1990, Nauchn. Inf. 68, 92

Gigosos M.A., Mar S., Pérez C., I. de la Rosa, 1994, Phys. Rev. E 49, 1575

Griem H.R., 1974, Spectral Line Broadening by Plasma. Academic Press, New York

Hansen J.E., Persson W., 1987, Phys. Scr. 36, 602

Heacox W.D., 1979, ApJS 41, 675

Konjević N., Uzelac N.I., 1990, JQSRT 44, 61

Konjević N., Wiese W.L., 1990, J. Phys. Chem. Ref. Data 19, 1307

Lesage A., Abadie D., Miller M.H., 1989, Phys. Rev. A 40, 1367

Lesage A., Miller M.H., Richou J., Bach T., 1981, in Spectral Line Shapes. In: Wende B., de Gruyter W. (eds.), Berlin,
New York, p. 257

Manola S., Konjević N., Richou J., Lebrun J. L., Lesage A., 1988, Phys. Rev. A38, 5742

Mar S., Gigosos M.A., de la Rosa I., Pérez C., 1992, 11th ICSLS, A23, Carry le Rouet, France

Miller M.H., Lesage A., Abadie D., 1981, Phys. Rev. A 25, 2064

Nick K.P., Helbig V., 1986, Phys. Scr. 33, 55

Pittman T.L., Konjević N., 1986, JQSRT 35, 247

Richou J., Manola S., Lebrun J.L., Lesage A, 1984, Phys. Rev. A29, 3181

Sahal-Bréchot S., 1969a, A\&A 1, 91

Sahal-Bréchot S., 1969b, A\&A 2, 322

Vitel Y., Skowronek M., 1987, J. Phys. B 20, 6493

Whitford A.E., 1962, AJ 67, 640 